\title{
Leukocyte distribution in the equine endometrium as a response to acute induced endometritis
}

\author{
Charlotta Oddsdóttir, Sionagh Smith and Elaine D. Watson \\ Division of Veterinary Clinical Studies, Royal (Dick) School of Veterinary Studies, University of Edinburgh, Easter Bush Veterinary Centre, Midlothian
}

\begin{abstract}
Summary
Endometritis is an important cause of fertility problems in the mare, and all mares develop endometritis following breeding but reproductively normal mares will clear the inflammation. The histological pattern during endometritis in the mare has been described qualitatively for diagnostic purposes, but the distribution of leukocytes has not previously been described. In this study, endometrial biopsies were collected from five mares during oestrus and dioestrus, and then 20 hours after inducing S. zooepidemicus endometritis in oestrus and dioestrus. Four mares were also bred to a stallion, providing biopsies from breeding-induced endometritis, 20 hours after breeding. Computerized image analysis was used to count inflammatory cells in the luminal epithelium, stratum compactum and stratum spongiosum of the endometrium. Lymphocyte numbers were higher in control samples during oestrus than during dioestrus, but were higher in streptococcal endometritis in oestrus and dioestrus than during breeding-induced endometritis. The same pattern applied to eosinophil numbers, whereas neutrophil numbers were lower during endometritis in dioestrus than during endometritis in oestrus.
\end{abstract}

Keywords: Mare, endometrium, endometritis, leukocytes, lymphocytes, reproduction

\section{Leukozytenverteilung im equinen Endometrium als Reaktion auf eine akute induzierte Endometritis}

Die Endometritis stellt eine wichtige Ursache für Fertilitätsprobleme der Stute dar. Zwar entwickeln nahezu alle Pferde infolge einer Belegung eine Entzündung des Endometriums, diese heilt jedoch bei reproduktiv gesunden Tieren durch Selbstreinigungsvorgänge komplikationslos ab. Das histologische Bild einer equinen Endometritis ist im Rahmen diagnostischer Untersuchungen zwar qualitativ umfassend dokumentiert, es existiert jedoch bislang keine Beschreibung über das Verteilungsmuster der Leukozyten. In der vorliegenden Studie wurden von 5 Stuten Endometriumbiopsien zunächst im Östrus und Diöstrus gewonnen, und danach 20 Stunden nach Induzierung einer Endometritis durch Sc. zooepidemicus zu den gleichen Zyklusständen. Darüber hinaus wurde bei 4 Tieren eine Endometritis durch Belegung induziert, 20 Stunden nach dem Natursprung erfolgte die Biopsienentnahme. Mittels computergesteuerter Bildanalyse erfolgte die Auszählung der Entzündungszellen im luminalen Epithel sowie im Stratum compactum und im Stratum spongiosum des Endometriums. Innerhalb der Kontrollproben konnte im Östrus eine höhere Lymphozytenzahl als im Diöstrus nachgewiesen werden. Die Streptokokken-Endometritis zeigte sowohl im Östrus als auch im Diöstrus eine höhere Lymphozyłenzahl als die Endometritis nach Belegung. Während die Verteilungsmuster der eosinophilen Granulozyten denen der Lymphozyten entsprechen, wurden im Verlauf der Endometritis im Diöstrus weniger neutrophile Granulozyten beobachtet als im Östrus.

Schlüsselwörter: Stute, Endometrium, Endometritis, Leukozyten, Lymphozyten, Reproduktion

\section{Introduction}

Mares show a varied clinical inflammatory response during endometritis. All mares develop endometritis following breeding but reproductively normal mares recover from inflammation within 48-72 hours (Watson 2000). The most commonly isolated bacterium from endometritis is Streptococcus equi subsp. zooepidemicus ( $\mathrm{S}$. zooepidemicus) (Ricketts et al. 1993). During oestrus there is an increase in the activity of uterine-derived neutrophils in mares resistant to persistent endometritis making them more able to clear a uterine inflammation than during dioestrus (Asbury and Hansen 1987). A persistent endometritis can result in an early pregnancy loss unless the inflammation is treated before the conceptus reaches the uterus.

Endometritis is traditionally characterized as either acute with mainly neutrophils, or chronic with mostly lymphocytes, although superimposed acute reactions also occur, where lymphocytic infiltrates and some neutrophil infiltration are seen simultaneously (so called "chronic active"). In chronic reac- tions, lymphocytes are often accompanied by scattered eosinophils (Kenney 1978). There are no previous studies investigating the influence of aetiology (bacterial versus breeding induced) on the pattern of cellular infiltrate in endometritis; nor has the potential effect of stage of oestrus cycle been examined.

The aim of this study was to utilise experimental models to describe the histopathology of different types of endometritis. A histological comparison between a pure bacterial endometritis and a breeding-induced endometritis was carried out, to determine if there is a difference in endometrial cellular infiltrates in the different types of endometritis, and at different stages of the oestrous cycle.

\section{Materials and methods}

Five reproductively healthy mares of various breeds were studied through four consecutive oestrous cycles. Control endometrial biopsies from each mare were collected at 
oestrus and dioestrus before bacterial endometritis was induced in oestrus and dioestrus, ensuring that full recovery was achieved before proceeding to the next stage of the protocol. Biopsies were collected 20 hours after induction of endometritis. Finally four of the mares were mated to a healthy stallion and endometrial biopsies were collected 20 hours later. An image analysis program was used to count lymphocytes, neutrophils and eosinophils in the luminal epithelium (LE), stratum compactum (SC) and stratum spongiosum (SS). The numbers of cells (each cell type) were compared for each stage of the oestrous cycle and each induction model by general linear modelling, taking significance at $\mathrm{p}<0.05$.

\section{Results}

In the LE and SC (Figure 1), lymphocyte numbers were significantly higher in control samples during oestrus than in dioestrus, whereas in the SS they were lower in oestrus than

Lymphocytes in stratum compactum

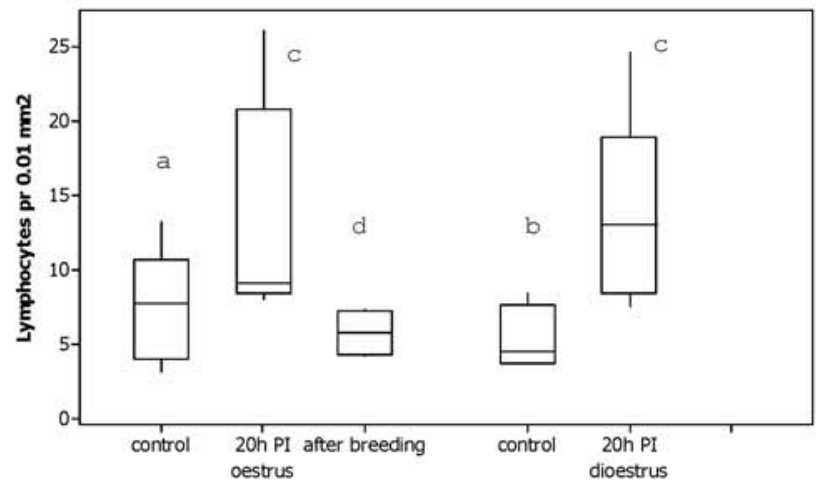

Fig 1 Boxplot illustrating the number of lymphocytes $/ 0.01 \mathrm{~mm}^{2}$ in stratum compactum of equine endometrial biopsies. Values labelled a are significantly $(p=0.005)$ higher than $b$, and values labelled $c$ are significantly $(p<0.001)$ higher than $a, b$ and d. 20 h Pl: 20 hours after uterine inoculation with S. zooepidemicus. After breeding: 20 hours after natural breeding to a stallion.

Boxplot Darstellung der Lymphozytenzahl/0,01 mm² im Stratum compactum der equinen Endometriumbiopsien. Mit a gekennzeichnete Werte sind signifikant $(p=0,005)$ höher als diese mit $b$. Mit c gekennzeichneten Werte sind signifikant $(p<0,001)$ höher als diese mit $a, b$ und d. 20h PI: 20 Stunden nach intrauteriner Verabreichung von S. zooepidemicus. After breeding: 20 Stunden nach Belegung durch einen Hengst.

in dioestrus (Figure 2). There was a significant increase in lymphocyte numbers in the LE and SC during streptococcal endometritis in oestrus and dioestrus when compared to control. There was a significant increase in lymphocyte numbers in the SS during streptococcal endometritis in oestrus, but not in dioestrus. In the LE, lymphocyte numbers after breeding at oestrus were higher than in control samples at oestrus, but no significant increase was seen in the SC and SS.

In the LE and SC, the number of neutrophils was increased in streptococcal endometritis in oestrus and dioestrus, but even though the increase was often substantial, in most cases statistical analysis was not possible, as no neutrophils were found in the control samples. In the SC and SS, neu- trophil numbers were significantly higher than during streptococcal endometritis during dioestrus but did not differ from streptococcal endometritis in oestrus. Eosinophils were only occasionally seen in the LE, but in the SC there were increased numbers in all three types of induced endometritis, but changes were not significant. In the SS there was a significant increase in eosinophil numbers during streptococcal endometritis during oestrus and dioestrus, but not after breeding. The biggest increase occurred in streptococcal endometritis in dioestrus, which was significantly greater than in the other types of endometritis.

To conclude, it is apparent that lymphocytes are present in larger numbers in the equine endometrial stroma during oestrus than during dioestrus. Lymphocytes react within the more acute phase of endometritis, both during oestrus and dioestrus, and in greater numbers during streptococcal endometritis than in breeding-induced endometritis. Neutrophils are found, as expected, to take part in streptococcal and breeding-induced endometritis, but fewer numbers

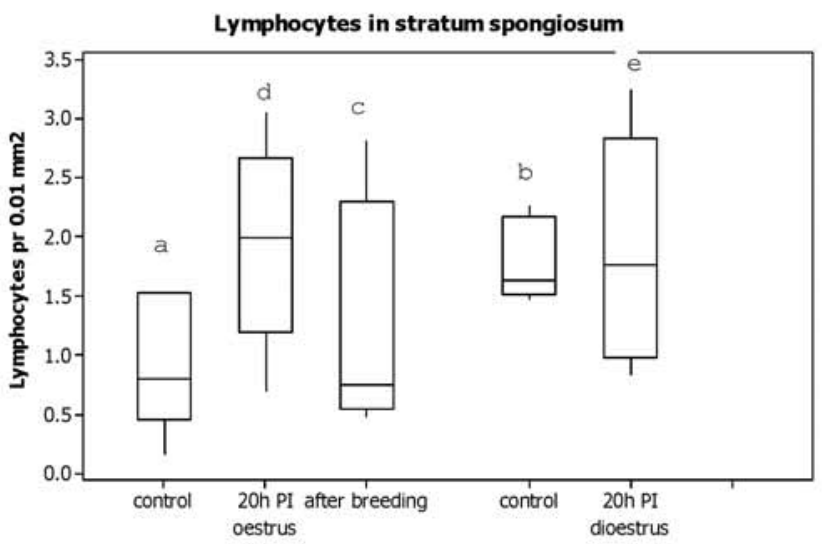

Fig 2 Boxplot illustrating the number of lymphocytes $/ 0.01 \mathrm{~mm}^{2}$ in stratum spongiosum of equine endometrial biopsies. Values labelled $a$ are significantly $(p<0.005)$ lower than $b$. Values labelled $c$ are significantly $(p<0.01)$ lower than e. Values labelled $d$ are significantly higher than a $(p<0.001)$, and $c(p<0.005)$. 20h PI: 20 hours after uterine inoculation with S. zooepidemicus. After breeding: 20 hours after natural breeding to a stallion.

Boxplot Darstellung der Lymphozytenzahl/0,01 mm² im Stratum spongiosum der equinen Endometriumbiopsien. Mit a gekennzeichnete Werte sind signifikant $(p<0,005)$ niedriger als diese mit $b$. Mit $c$ gekennzeichnete Werte sind signifikant $(p<0,01)$ niedriger als diese mit e. Mit $d$ gekennzeichnete Werte sind signifikant $(p<0,001)$ höher als diese mit a $(p<0,001)$ und $c(p<0,005)$. 20h Pl: 20 Stunden nach intrauteriner Verabreichung von S. zooepidemicus. After breeding: 20 Stunden nach Belegung durch einen Hengst.

are observed during endometritis in dioestrus than oestrus. Eosinophils also increase in numbers during endometritis, but are more numerous in response to $\mathrm{S}$. zooepidemicus than to breeding. Therefore, it seems that lymphocytes and eosinophils arrive in the endometrium within 20 hours of inflammatory stimulus, and that their reaction is more dependent on the type of stimulus than on the stage of the oestrous cycle. On the other hand, the reaction of neutrophils seems to be more dependent on the stage of the oestrous cycle, as they are more numerous during both breeding-induced and streptococcal endometritis during oestrus, than during streptococcal endometritis in dioestrus. 


\section{References}

Asbury A. C. and Hansen P. J. (1987) Effects of susceptibility of mares to endometritis and stage of cycle on phagocytic activity of uterine-derived neutrophils. J. Reprod. Fert. Suppl. 35, 311-316

Kenney R. M. (1978) Cyclic and pathologic changes of the mare endometrium as detected by biopsy, with a note on early embryonic death. J. Am. Vet. Med. Assoc. 172, 241-262

Ricketts S. W., Young A. and Medici E. B. (1993) Uterine and clitoral cultures. In Equine Reproduction. Eds A. O. McKinnon and J. L. Voss. Williams \& Wilkins, Philadelphia, 266-302
Watson E. D. (2000) Post-breeding endometritis in the mare.

[Review] [94 refs]. Animal Reprod. Sci. 60, 221-232

\section{Charlotta Oddsdóttir}

Division of Veterinary Clinical Studies

Royal (Dick) School of Veterinary Studies

University of Edinburgh

Easter Bush Veterinary Centre

Easter Bush, Midlothian EH25 9RG

c.oddsdottir@sms.ed.ac.uk

\title{
Activities of matrix metalloproteinases-9 and -2 in uterine fluid during induced equine endometritis
}

\author{
Charlotta Oddsdóttir', Simon C. Riley², Rosemary Leask², Dylan R. Edwards ${ }^{3}$ and Elaine D. Watson ${ }^{7}$
}

Division of Veterinary Clinical Studies, Royal (Dick) School of Veterinary Studies, University of Edinburgh, Easter Bush Veterinary Centre, Easter Bush, Midlothian', Centre for Reproductive Biology, Reproductive and Developmental Sciences, University of Edinburgh ${ }^{2}$ and School of Biological Sciences, University of East Anglia ${ }^{3}$

\begin{abstract}
Summary
Chronic degenerative changes to the endometrium include endometrial fibrosis, involving a deposition of fibrous tissue in the endometrial stroma and around the endometrial glands. In this study it is hypothesised that endometrial fibrosis is a result of extracellular matrix (ECM) remodelling following endometritis involving MMP-9 and -2 and the tissue inhibitors of MMPs (TIMPs). Endometrial biopsies and low volume uterine flushes were collected from five mares at oestrus and dioestrus before inducing endometritis. Endometritis was induced by introducing Streptococcus zooepidemicus into the uterus in oestrus and dioestrus, and by breeding the mares in oestrus. Gelatin zymography on uterine lavage fluid revealed that basal activities of MMP-2 and MMP-9 did not differ significantly between oestrus and dioestrus. A significant increase $(p<0.05)$ in MMP-9 and -2 activities was detected post-inoculation in oestrus and dioestrus, and post-breeding in oestrus when compared to controls. In situ zymography demonstrated MMP-9 activity in eosinophils in endometrial biopsies. Basal activity of TIMP-2 was significantly higher $(\mathrm{p}<0.05)$ during dioestrus than during oestrus, and activity decreased during induced endometritis. The study showed that MMP-9 and MMP-2 are likely to play a role in the repair processes following endometritis and that MMP-9 is secreted by eosinophils in the endometrial stroma. Furthermore, the inhibitory activity of TIMP-2 is decreased during endometritis, in concert with the increased activity of MMP-9 and -2.
\end{abstract}

Keywords: Mare, endometritis, fibrosis, matrix metalloproteinases, TIMPs, reproduction

\section{Aktivität der Matrix Metalloproteinasen MMP-9 und MMP-2 in Uterusspülproben im Verlauf einer induzierten equinen End- ometritis}

Die endometriale Fibrose, eine chronisch-degenerative Veränderungen des Endometriums, ist durch eine Einlagerung von fibrösem Gewebe sowohl in das endometriale Stroma als auch um die endometrialen Drüsen gekennzeichnet. In der vorliegenden Studie wird angenommen, dass die endometriale Fibrose das Ergebnis eines durch die Endometritis ausgelösten Umbaus der extrazellulären Matrix ist, an welchem MMP-9 und MMP-2 sowie deren Inhibitoren (TIMPs) beteiligt sind. Als Kontrolle dienten im Östrus und Diöstrus entnommene Endometriumbiopsien und kleinvolumigen Uterusspülproben von 5 Stuten vor Endometritisinduzierung. Anschließend wurde eine Endometritis mittels intrauteriner Verabreichung von Streptococcus zooepidemicus zum Zeitpunkt des Östrus und des Diöstrus beziehungsweise durch eine Belegung im Östrus induziert. Mit Hilfe einer Gelatin-Zymographie konnten in den uterinen Spülproben keine signifikanten Unterschiede hinsichtlich der Grundaktivität von MMP-2 und MMP-9 zwischen Östrus und Diöstrus nachgewiesen werden. Im Vergleich zu den Kontrollproben konnte jedoch sowohl postinfektiös im Östrus und Diöstrus als auch nach der Belegung im Östrus ein signifikanter Anstieg $(p<0,05)$ der Aktivität von MMP-2 und MMP-9 beobachtet werden. Zudem zeigte die in situ Zymographie eine Aktivität von MMP-9 in den eosinophilen Granulozyten der Endometriumbioptate. Die Grundaktivität von TIMP-2 ist im Diöstrus signifikant höher $(p<0,05)$ als im Östrus, nimmt jedoch im Verlauf der induzierten Endometritis ab. Die Ergebnisse dieser Studie zeigen, dass MMP-9 und MMP-2 vermutlich eine Rolle bei Reparaturvorgängen infolge einer Endometritis spielen, wobei MMP-9 von den eosinophilen Granulozyten des endometrialen Stromas sezerniert wird. Darüber hinaus kann im Rahmen der Endometritis festgestellt werden, dass die hemmende Aktivität der TIMP2 mit steigender Aktivität der MMP-9 und -2 sinkt.

Schlüsselwörter: Stute, Endometritis, Fibrose, Matrix Metalloproteinasen, TIMPs, Reproduktion

\section{Introduction}

Endometrial fibrosis is a common chronic degenerative change seen in the endometrium of the mare and has detri- mental effects on fertility (Ricketts and Alonso 1991). Endometrial fibrosis is likely to result from events taking place during remodelling of the endometrial extracellular matrix (ECM). Endometrial remodelling is limited in the cyclic non- 
pregnant mare but is likely to occur following endometritis, which is commonly experienced by breeding mares (Watson 2000) as a reaction to semen and potentially pathogenic organisms. The most common cause of infectious endometritis in the mare is Streptococcus equi subsp. zooepidemicus (S. zooepidemicus) (Ricketts et al. 1993). In a normal mare, the inflammatory response is brief, peaking around $8 \mathrm{~h}$ after breeding and with very few neutrophils recovered at 48h (Katila 1995). However, approximately $15 \%$ of thoroughbred mares develop persistent endometritis (Zent and Troedsson 1998).

Endometrial remodelling in women takes place around menstruation and involves the expression, secretion and activation of matrix metalloproteinases (MMPs; (Salamonsen 2003). These proteases have the capacity to degrade all structural components of the ECM, including collagen and are regulated by the tissue inhibitors of MMPs (TIMPs), which also have been identified in human endometrium (Curry Jr. and Osteen 2003). The activities of the gelatinases MMP-9 and -2 play a role in the formation of endometrial cups during equine pregnancy (Vagnoni et al. 1995) and MMP-2 has been identified around fibrotic glands of the non-pregnant equine endometrium (Walter et al. 2005). However, the secretion of these MMPs in the normal non-pregnant equine endometrium during the oestrous cycle, and during endometritis has not previously been investigated.

We hypothesise that tissue remodelling and repair during and following equine endometritis in the reproductively normal mare involves regulation of MMP-9 and MMP-2 activities.

\section{Materials and methods}

Five healthy mares of various breeds were studied through four consecutive oestrous cycles. They were reproductively normal as confirmed by negative microbiological culture of endometrial and clitoral swabs, the absence of inflammatory cells in endometrial and vaginal smears and a histopathological assessment category I-IIA (Kenney and Doig 1986) of H\&E stained endometrial biopsies.

The experimental design used was a crossover case-control study utilizing each animal as its own control. Transrectal scanning of the reproductive tract was carried out daily on each animal to follow the progress of their reproductive cycles, and samples were collected at the appropriate stage of the oestrous cycle. A uterine lavage was collected from each mare at the beginning of oestrus (one or more ovarian follicles with diameter $35 \mathrm{~mm}$, coinciding with endometrial oedema) and in the following dioestrus on day nine post-ovulation. Uterine lavage was collected from mares as previously described (Nikolakopoulos and Watson 1999). The lavage fluid was collected into $15 \mathrm{ml}$ tubes and centrifuged at $800 \mathrm{~g}$ for 15 minutes. The supernatant was decanted into a clean tube and stored at $-20^{\circ} \mathrm{C}$. Bacterial endometritis was then induced by inoculating the uterus via a sterile insemination pipette with $10^{6} \mathrm{cfu}$ of $\mathrm{S}$. zooepidemicus at the beginning of oestrus in three mares and on day nine post-ovulation in two mares. A uterine lavage was collected from each mare five hours after inoculation, and again 20 hours after inoculation. After collecting samples, all mares were monitored daily for clinical signs of endometritis, and mares that were inoculated in dioestrus received endometritis treatment to ensure recovery. Once all mares had recovered, confirmed by cytology and microbiology of endometrial swabs, inoculations were repeated so each mare had been inoculated both at oestrus and dioestrus. The sampling regime was repeated, and clinical monitoring and treatment were again carried out to ensure recovery. In the final stage of the protocol, endometritis was induced by mating four of the mares to a healthy stallion. Uterine lavage fluid was collected five hours and 20 hours post-mating.

The presence of gelatinase MMPs - 9 and -2 in uterine lavage fluid was investigated using gelatin substrate zymography as described previously (Riley et al. 1999). Activities of tissue inhibitors of MMPs (TIMPs) in uterine lavage fluid were analysed by reverse zymography as described by Riley et al. (1999). Statistical analyses were performed on relative densitometric values of MMP and TIMP bands using a paired ttest. Results were considered to be significant when $p<0.05$.

\section{Results}

Gelatin zymography detected MMP-9 and MMP-2 in uterine lavage fluid (Fig. 1a). Basal levels of MMP-9 (Fig. 1 b) and MMP-2 in control samples did not differ significantly between oestrus and dioestrus. After S. zooepidemicus inoculations and after mating, latent MMP-9 and MMP-2 activities were dramatically increased $(p<0.001$ in all cases). Measured activity of MMP-9 five hours post inoculation in oestrus was significantly lower than five hours post inoculation in dioestrus $(p<0.001)$ and five hours post mating $(p<0.05)$.

Reverse zymograms revealed the presence of TIMP- 1 and -2, and the glycosylated and unglycosylated forms of TIMP-3 in all uterine lavages (Fig. 2a). However, amounts of TIMP-2 were consistently and significantly higher $(p<0.05$; Fig. $2 b)$ in dioestrus control samples than at oestrus and activity in samples taken during endometritis tended to be lower than in control samples, with a significant reduction in TIMP-2 activity demonstrated five $(p<0.01)$ and $20(p<0.05)$ hours postinoculation in dioestrus.

\section{Discussion}

In this study it has been shown for the first time that the gelatinases MMP-9 and MMP-2 are induced during acute equine endometritis, both bacterial and breeding-induced. This suggests that they are involved in the tissue remodelling and repair process following an inflammatory response in the endometrium. Moreover, this is the first time that TIMP activities have been reported in the equine endometrium.

The secretion of basal MMP-9 and MMP-2 by the equine endometrium is low at oestrus and dioestrus and therefore it is unlikely that they play a major role during the normal equine oestrous cycle. This is not surprising as the equine oestrous cycle does not involve the same degree of remo- 
delling the human menstrual cycle, where increased MMP9 activity is associated with menstruation (Goffin et al. 2003).

In this study the response to uterine insult by upregulation of MMP secretion was rapid, and especially profound in the case of MMP-9. We suggest that these MMPs are important in the uterine inflammatory response and are rapidly and clo-
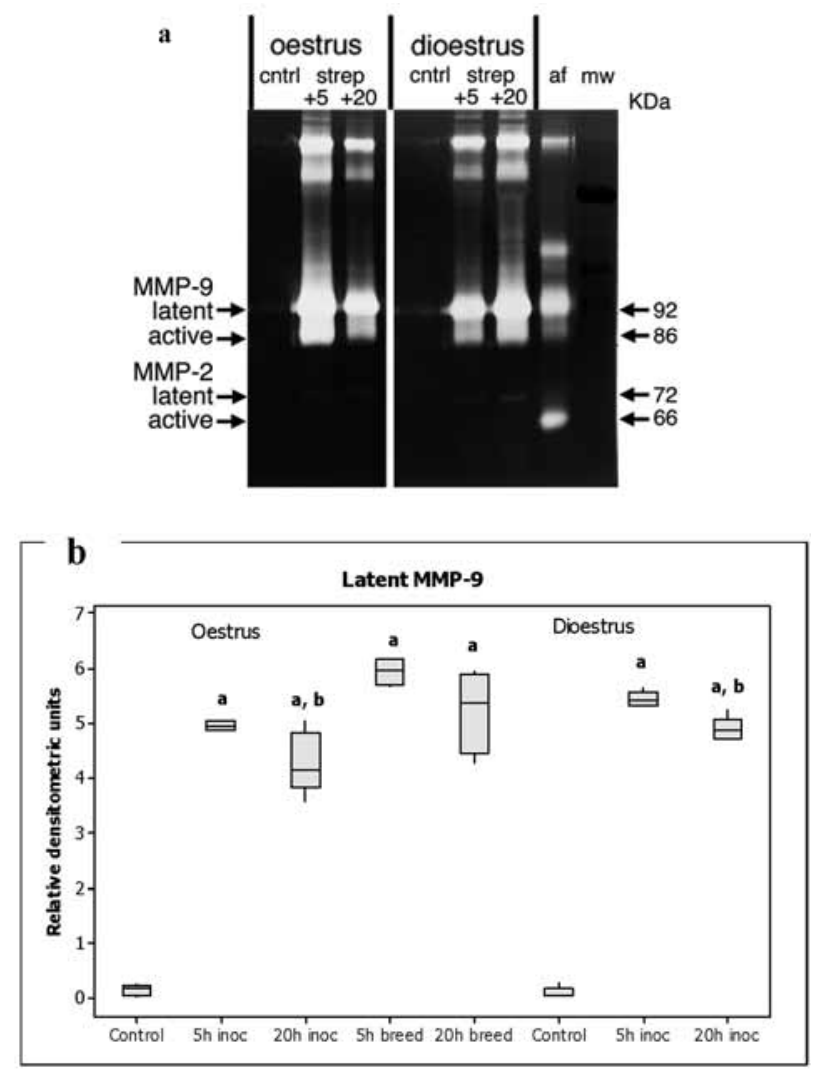

Fig 1 Boxplot illustrating the number of lymphocytes $/ 0.01 \mathrm{~mm}^{2}$ in stratum compactum of equine endometrial biopsies. Values labelled a are significantly $(p=0.005)$ higher than $b$, and values labelled $c$ are significantly $(p<0.001)$ higher than $a, b$ and d. 20 h PI: 20 hours after uterine inoculation with S. zooepidemicus. After breeding: 20 hours after natural breeding to a stallion.

Boxplot Darstellung der Lymphozytenzahl/0,01 mm² im Stratum compactum der equinen Endometriumbiopsien. Mit a gekennzeichnete Werte sind signifikant $(p=0,005)$ höher als diese mit $b$. Mit c gekennzeichneten Werte sind signifikant $(p<0,001)$ höher als diese mit $a, b$ und d. $20 \mathrm{~h} \mathrm{PI:} 20$ Stunden nach intrauteriner Verabreichung von S. zooepidemicus. After breeding: 20 Stunden nach Belegung durch einen Hengst.

sely regulated according to the stage of inflammation. It was shown that the inflammatory response following breeding at oestrus provoked a greater increase in MMP-9 activity than S. zooepidemicus inoculation at oestrus. Natural breeding introduces sperm as well as potentially pathogenic surface microorganisms into the uterus which might amount to an additive effect on MMP activity by these two inflammatory components. It is known that spermatozoa induce an inflammatory response in the uterus through compliment activation (Troedsson et al. 2001), but this is counteracted by an immunosuppressive effect on uterine neutrophils by seminal plasma (Alghamdi et al. 2004). MMP-9 expression in uterine lavage fluid demonstrated little variation between mares. This suggests precise regulation of MMP-9 expression associated with the profound inflammatory stimulation.

It was demonstrated that TIMPs were expressed in the mare endometrium, with activity of TIMP-2 at a higher level during dioestrus than during oestrus. The expression of TIMP-2 tended to decrease at the same time as an increase was seen in
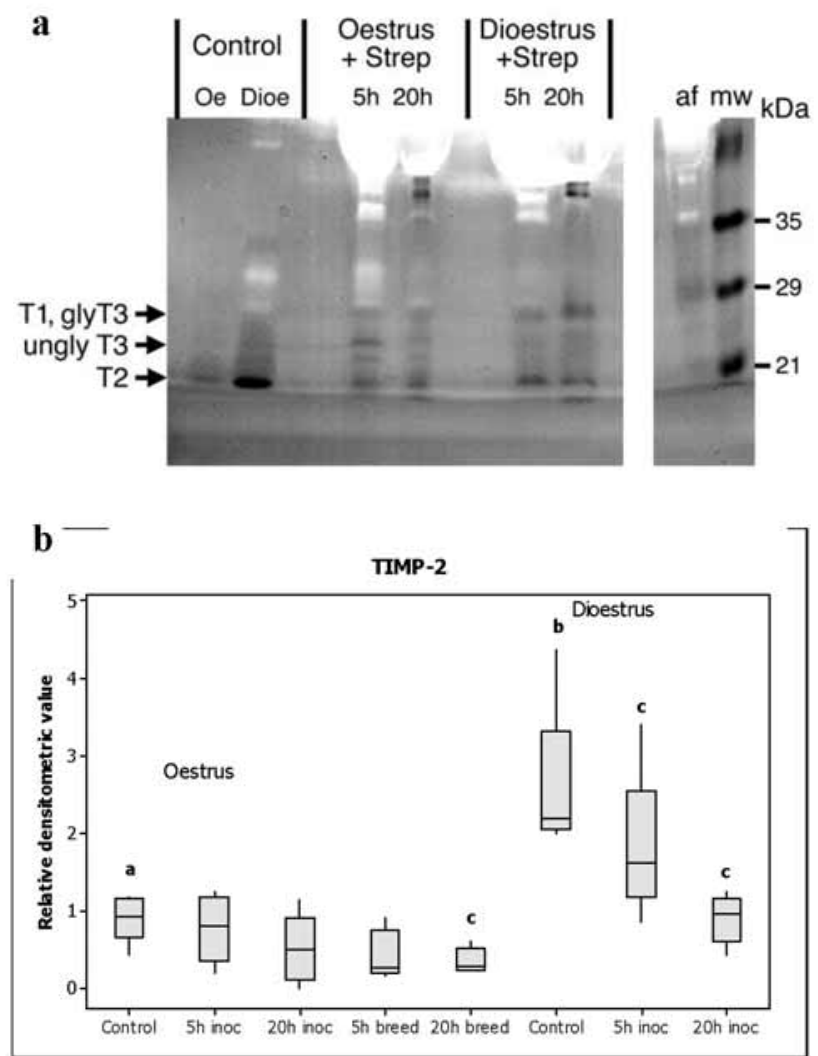

Abb 2 Boxplot illustrating the number of lymphocytes $/ 0.01 \mathrm{~mm}^{2}$ in stratum spongiosum of equine endometrial biopsies. Values labelled a are significantly $(p<0.005)$ lower than $b$. Values labelled $c$ are significantly $(p<0.01)$ lower than e. Values labelled $d$ are significantly higher than a $(p<0.001)$, and $c(p<0.005)$. 20h PI: 20 hours after uterine inoculation with $\mathrm{S}$. zooepidemicus. After breeding: 20 hours after natural breeding to a stallion.

Boxplot Darstellung der Lymphozytenzahl/0,01 $\mathrm{mm}^{2}$ im Stratum spongiosum der equinen Endometriumbiopsien. Mit a gekennzeichnete Werte sind signifikant $(p<0,005)$ niedriger als diese mit $b$. Mit $c$ gekennzeichnete Werte sind signifikant $(p<0,01)$ niedriger als diese mit e. Mit d gekennzeichnete Werte sind signifikant $(p<0,001)$ höher als diese mit a $(p<0,001)$ und $c(p<0,005)$. 20h Pl: 20 Stunden nach intrauteriner Verabreichung von S. zooepidemicus. After breeding: 20 Stunden nach Belegung durch einen Hengst.

MMP-9 and -2 activities after endometritis was induced. This shows a different pattern of regulation to the human endometrium, where a fluctuation in MMPs is not met by a fluctuation in TIMP-2 activity during menstruation (Goffin et al. 2003).

In conclusion, this study has indicated that collagen remodelling by matrix metalloproteinases -9 and -2 and their regulator by TIMP-2 takes place in the equine endometrium during acute endometritis, and that the process is highly 
regulated. An alteration in the regulation of these MMPs may lead to deposition of collagen as is seen in endometrial fibrosis.

\section{References}

Alghamdi A. S., Foster D. N. and Troedsson M. H. (2004) Equine seminal plasma reduces sperm binding to polymorphonuclear neutrophils (PMNs) and improves the fertility of fresh semen inseminated into inflamed uteri. Reproduction 127, 593-600

Curry T. E. Jr. and Osteen K. G. (2003) The matrix metalloproteinase system: changes, regulation, and impact throughout the ovarian and uterine reproductive cycle. Endocr. Rev. 24, 428-465

Goffin F., Munaut C., Frankenne F., Perrier D. S., Beliard A., Fridman V., Nervo P., Colige A. and Foidart J. M. (2003) Expression pattern of metalloproteinases and tissue inhibitors of matrix-metalloproteinases in cycling human endometrium. Biology of Reproduction 69, 976-984

Katila T. (1995) Onset and duration of uterine inflammatory response of mares after insemination with fresh semen. Biol. Reprod. Monogr. 1, 515-517

Kenney R. M. and Doig P. A. (1986) Equine endometrial biopsy. In Current Therapy in Theriogenology, p. 723. Ed D. A. Morrow. Philadelphia: W. B. Saunders.

Nikolakopoulos E. and Watson E. D. (1999) Uterine contractility is necessary for the clearance of intrauterine fluid but not bacteria after bacterial infusion in the mare. Theriogenology 52, 413-423

Ricketts S. W. and Alonso S. (1991) Assessment of the breeding prognosis of mares using paired endometrial biopsy techniques. Equine Vet. J. 23, 185-188

Ricketts S.W., Young A. and Medici E. B. (1993) Uterine and clitoral cultures. In Equine Reproduction, Eds A. O. McKinnon \& J. L. Voss. Philadelphia, Williams \& Wilkins, 266-302
Riley S. C., Leask R., Chard T., Wathen N. C., Calder A. A. and Howe D. C. (1999) Secretion of matrix metalloproteinase-2, matrix metalloproteinase- 9 and tissue inhibitor of metalloproteinases into the intrauterine compartments during early pregnancy. Mol. Hum. Reprod. 5, 376-381

Salamonsen L. A. (2003) Tissue injury and repair in the female human reproductive tract. Reproduction 125, 301-311

Troedsson M. H., Loset K., Alghamdi A. M., Dahms B. and Crabo B. $G$. (2001) Interaction between equine semen and the endometrium: the inflammatory response to semen. Anim. Reprod. Sci. 68, 273-278

Vagnoni K. E., Ginther O. J. and Lunn D. P. (1995) Metalloproteinase activity has a role in equine chorionic girdle cell invasion. Biology of Reproduction 53, 800-805

Walter I., Handler J., Miller I. and Aurich C. (2005) Matrix metalloproteinase 2 (MMP-2) and tissue transglutaminase (TG 2) are expressed in periglandular fibrosis in horse mares with endometrosis. Histol. Histopathol. 20. 1105-1113.

Watson E. D. (2000) Post-breeding endometritis in the mare. [Review] [94 refs]. Anim. Reprod. Sci. 60, 221-232

Zent W. W. and Troedsson M. H. (1998) Postbreeding uterine fluid accumulation in a normal population of thoroughbred mares: $A$ field study. Proc. .Am. Assoc. Equine Pract. 4465

Charlotta Oddsdóttir

Division of Veterinary Clinical Studies

Royal (Dick) School of Veterinary Studies

University of Edinburgh, Easter Bush Veterinary Centre

Easter Bush, Midlothian EH25 9RG

c.oddsdottir@sms.ed.ac.uk

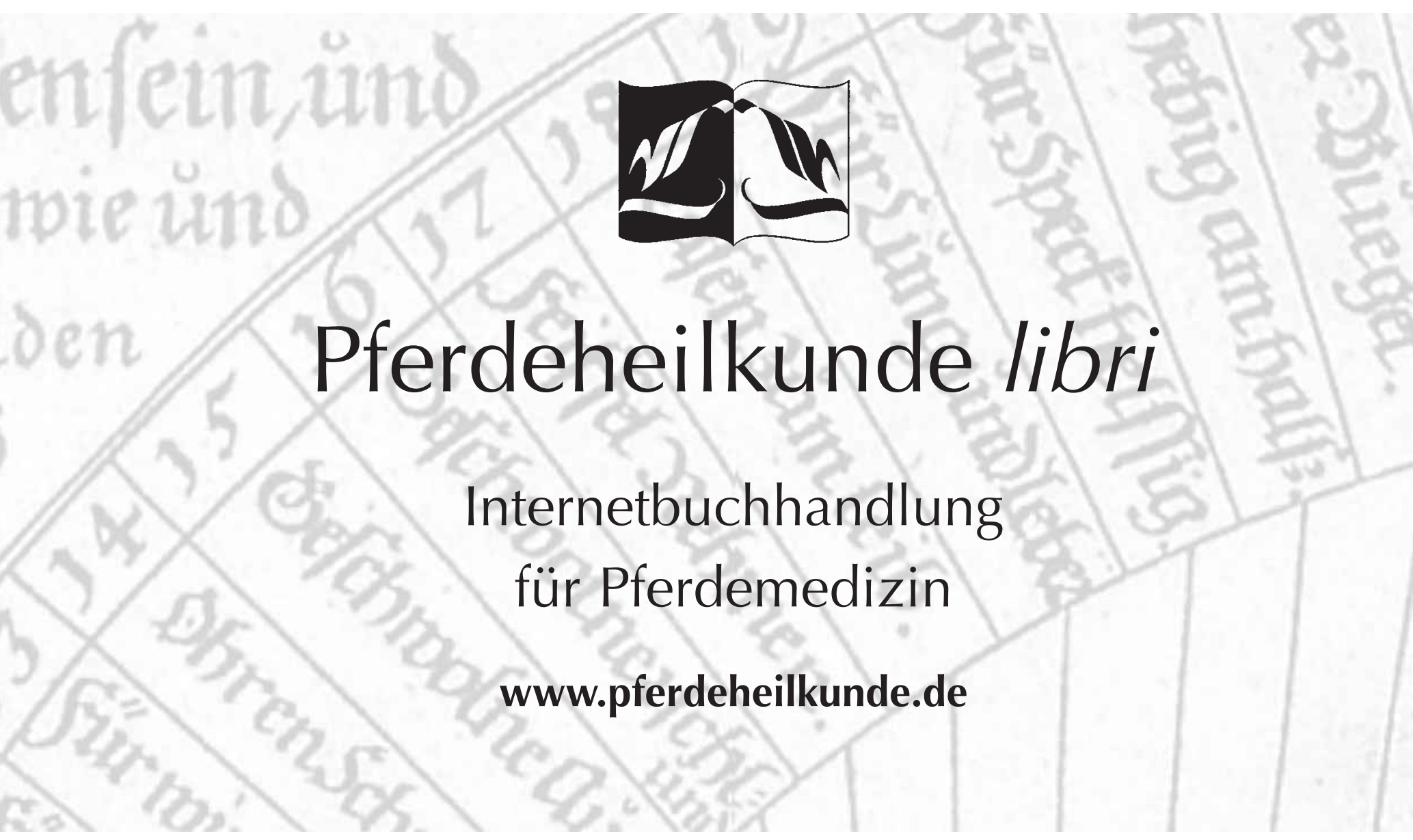

